\title{
Immunoglobulin Production in Vitro in Major Depression: A Pilot Study on the Modulating Action of Endogenous Cortisol
}

\author{
Frans W. Kok, Cobi J. Heijnen, Jan A. Bruijn, \\ Herman G.M. Westenberg, and Jan M. van Ree
}

To investigate the possible differential sensitivity of hydrocortisone ( $\mathrm{HCO}$ ) on immunoglobulin (Ig) production in depression in relation to endogenous cortisol levels, blood was obtained at 8 $A M$ and $4 P M$ from 10 inpatients with major depression according to DSM-III-R criteria and 10 age-and sex-matched healthy subjects. Peripheral blood lymphocytes were cultured in the presence of graded concentrations $\left(10^{-9}-10^{-5 M}\right)$ of HCO to study the effect on immunoglobulin (IgG and IgM) synthesis. In addition, peripheral blood lymphocytes were cultured in the presence of pokeweed mitogen ( $P W M)$ to study any additional effect of graded concentrations of HCO $\left(10^{-9}-10^{-5 M}\right)$ on $1 g G$ and IgM synthesis. Mean plasma cortisol levels at both time points were higher in patients compared to controls. $\mathrm{HCO}-$ preferentially at concentrations of $10^{-8}$ $10^{-5}$ molar-stimulated IgG and IgM production in controls, except for IgM production in the 8 AM samples, when the cells were cultured in the absence of PWM. Under these culture conditions, HCO stimulated IgG but not IgM synthesis in depressed patients. PWM-driven IgG and IgM synthesis in controls was stimulated by HCO in both the $8 \mathrm{AM}$ and the 4 PM samples. In patients PWM driven IgG synthesis was stimulated by HCO in the 8 AM but not in the 4 PM samples. PWM-stimulated IgM synthesis was not augmented by $\mathrm{HCO}$ in depressed patients. We conclude that a differential sensitivity to the effects of $\mathrm{HCO}$ exists in in vitro $\operatorname{IgG}$ and $\operatorname{IgM}$ synthesis between depressed patients and controls. Furthermore, we suggest that immunocompetent cells of depressed patients possess corticosteroid-resistant properties.

Key Words: Immunoglobin, depression, cortisol, corticosteroid, antigen

\footnotetext{
From the Department of Psychiatry, Academic Hospital (FWK. HGMW) and the Department of Pharmacology, Rudolf Magnus Institute (JMvR). University of Utrecht; the Department of Pediatric Immunology. University Hospital for Children and Youth "het Wilhelmina Kinderziekenhuis". Utrecht (CJH): and the Department of Psychiatry. University Hospital Rotterdam-Dijkzigt, Rotterdam (JAB), the Netherlands.

Address reprint requests to J.M. van Ree, Department of Pharmacology, Rudolf Magnus Institute. University of Utrecht. Universiteitsweg 100.3584 CG Utrecht. the Netherlands.

Received November 30, 1992, revised September 19.1994.
}

\section{Introduction}

The modulating action of glucocorticoids on the immune response is expressed at various levels (Cupps and Fauci 1982). Glucocorticoids exert inhibiting effects on the expression of immune response antigen on the surface, which plays a role in the interaction of $B$ cells with T cells (McMillan et al 1988), on the synthesis of cytokines-e.g., interleu- 
kin-1 (IL-1), interleukin-2 (II-2), and interleukin-6 (IL-6) (Snyder and Unanue 1982; Arya et al 1984; Staruch and Wood 1985; Woloski et al 1985; Grabstein et al 1986) and on cytokine receptors (Reed et al 1986; Akahoshi et al 1988). Furthermore, glucocorticoids induce suppression of B cell activation and proliferation (Bowen and Fauci 1984; Cupps et al 1985) and T cell proliferation (Gillis et al 1979). They exhibit a differential effect on the function of $T$ helper and $\mathrm{T}$ suppressor cells (Bradley and Mishell 1981). The above-described mechanisms of glucocorticoids may be integrated in the role glucocorticoids play in modulating the effects on immunoglobulin (Ig) synthesis. In the pokeweed mitogen (PWM)-driven Ig synthesis by cultured lymphocytes, physiological as well as supraphysiological doses of glucocorticoids have an enhancing property, provided that they are present at the beginning of the culture (Fauci et al 1977; Cooper et al 1979; Brieva et al 1983). In addition, Ig production can be induced by glucocorticoids in lymphocytes cultured in vitro in the presence of fetal calf serum (FCS), without the addition of any other mitogen (Smith et al 1972; Grayson et al 1981; Orson et al 1983). FCS seems to be required for this stimulating effect (Sierakowski and Goodwin 1988). Disturbances in hypothalamo-pituitaryadrenal (HPA) axis function have been described in affective disorders (Carroll et al 1976a,b; Fang et al 1981; Pfohl et al 1985; Roy et al 1987; Coppen and Metcalfe 1987; Ball et al 1987; Kathol et al 1989). Data on a relationship between the hypercortisolemia present in depressed patients and disturbances in immune reactivity in vitro are conflicting. An inverse relationship between mitogenic lymphocytic response and plasma cortisol in depressed patients has been reported by Schleifer et al (1984), whereas others did not find an association between immune function and plasma cortisol (Kronfol et al 1986; Nerozzi et al 1989). In assessing immune reactivity in relation to variances in endogenous cortisol, we studied the relationship between the circadian rhythm of cortisol and the in vitro modulating effect of this hormone on in vitro Ig synthesis in depressed patients and age- and sex-matched controls. We hypothesized that the expected higher plasma cortisol levels in patients would render in vitro patient lymphocytes to be less sensitive to the effects of hydrocortisone than cells obtained from controls. In addition. if the circadian rhythm of the HPA axis was to be preserved in patients, we expected to find differences in immunoreactivity within groups.

\section{Materials and Methods}

\section{Subjects}

The protocol was approved by the ethics review committees of the Academic Hospital Utrecht and the Academic Hospital Rotterdam-Dijkzigt. Patients and controls gave informed consent to participate in the study. Ten inpatients suffering from unipolar depressive illness participated in this study. All patients were given the diagnosis major depressive disorder according to DSM-III-R criteria (APA 1987). Ten sex- and age-matched subjects volunteered as controls in this study; they were an unpaid community sample. All participants were free from clinical disorders associated with immunological alterations. The depressed patients had not taken psychotropic medication at least 7 days prior to entry into the study. One patient used oral contraceptives. None of the control subjects used medication, except for one on oral contraceptives.

\section{Blood Sampling}

Heparinized blood samples were taken from every participant at $8 \mathrm{AM}$ and at $4 \mathrm{PM}$ by venipuncture, with an interval of 1-3 days.

\section{Psychometry}

Hamilton depression rating scale (Hamilton 1960) scores of all subjects were obtained on the day of the second blood sample.

\section{Corticosteroids}

Hydrocortisone (HCO) was dissolved in $100 \%$ ethanol, diluted in RPMI 1640 medium (GIBCO), and added to the cultures.

\section{Isolation of Mononuclear Cells}

Heparinized blood was diluted 1:1 (vol/vol) with minimal essential medium (MEM; GIBCO) supplemented with streptomycin $100 \mu \mathrm{g} / \mathrm{ml}$ and penicillin $100 \mathrm{U} / \mathrm{ml}$. Mononuclear cell suspensions were obtained by Ficoll-hypaque (Pharmacia) density centrifugation and were washed twice with MEM. The immune function tests were performed in unpaired experiments.

\section{Determination of Ig Synthesis}

$5 \times 10^{5}$ peripheral blood lymphocytes (PBL) in a final volume of $0.6 \mathrm{ml}$ medium were cultured in duplicate in round-bottomed $100 \times 16 \mathrm{~mm}$ polystyrene tubes in RPMI 1640 containing $20 \%$ FCS (GIBCO), 2 Mm glutamine, $100 \mu \mathrm{g} / \mathrm{ml}$ streptomycin, and $100 \mathrm{U} / \mathrm{ml}$ penicillin. This will be referred to as complete medium. $\mathrm{HCO}$ in a final concentration range from $10^{-9}-10^{-5} \mathrm{M}$ or an equal amount of complete medium, to provide for basal immunoglobulin synthesis, was added to all cultures with or without PWM (GIBCO). PWM was dissolved in RPMI 1640 and $20 \%$ FCS in a final concentration of $20 \mu \mathrm{g} / \mathrm{ml}$. Cells were cultured in $5 \% \mathrm{CO}_{2}$ for 7 and 10 days in the presence or absence of PWM, respectively.

IgG and IgM were measured by an ELISA technique (Bloem et al 1984). Briefly, after coating the polyvinyl- 
chloride culture plates (Titertek) with rabbit antisera against human IgG (Dako) and IgM (CLB, Amsterdam) supernatants in six different dilutions were incubated, followed by incubation with peroxidase-labeled conjugated rabbit antihuman antibodies (Dako). Between each incubation period the plates were washed three times with PBS containing $0.05 \%$ Tween- 20 . The culture plates were read by an ELISA reader at $492 \mathrm{~nm}$.

Plasma cortisol levels were assayed by a RIA as described by Thijssen et al (1980).

\section{Statistics}

$T$ tests were performed to test for the effect of time on basal immunoglobulin production in cultures from cells sampled at $8 \mathrm{AM}$ and $4 \mathrm{PM}$. The same statistical method was used to test for any difference in Hamilton rating scale scores between depressed patients and controls. Analysis of the cortisol data was performed by using univariate analysis of variance (ANOVA), with the variables group and time included in the model.

Data on immunoglobulins were log-transformed before analysis. In all cultures, a $\mathrm{HCO}$ concentration of $10^{-5} \mathrm{M}$ caused a marked reduction of Ig production, obscuring any overall augmenting effect of HCO. Therefore these data were ignored in all analyses. A multivariate analysis of variance (MANOVA) was performed on the immunoglobulin production data. Three interaction terms were introduced in the analyses of these data. They included group, concentration, and time, to denote the patient and control group. $\mathrm{HCO}$ concentration, and time of sampling, respectively.

In any statistical test a $p$ value of .05 or less was considered statistically significant.

\section{Results}

All results are expressed as the mean \pm SEM.

\section{Demographics}

Eight female and two male patients participated in the study: their ages ranged from $32-62$ years ( $46.1 \pm 3.2$ years). The ages of eight female and two male controls ranged from $32-60$ years $(46.9 \pm 2.9$ years $)$.

\section{Psychometry}

Mean Hamilton rating scale depression score in patients was $26.2 \pm 1.3$ (range, $22-33$ ); the controls rated $1.2 \pm 0.3$ $(t=18.5, d f=18, p<.001)$.

\section{Plasma Cortisol Levels}

The mean plasma cortisol levels of patients and controls are summarized in Table 1. ANOVA on cortisol data revealed a
Table 1. Mean Plasma Cortisol Levels ${ }^{\prime}$

\begin{tabular}{lccc}
\hline & No. of & \multicolumn{2}{c}{ Sampling time } \\
\cline { 3 - 4 } Group & subjects & $8 \mathrm{AM}$ & $4 \mathrm{PM}$ \\
\hline Patients & 10 & $0.67 \pm 0.04$ & $0.47 \pm 0.06^{*}$ \\
Controls & 10 & $0.56 \pm 0.04$ & $0.34 \pm 0.03^{* *}$ \\
\hline
\end{tabular}

Concentrations are in $\mu \mathrm{mol} / \mathrm{l}$ and given as mean $\pm \mathrm{SEM}$.

${ }^{*} p<01$ and ${ }^{* *} p<.005$ as compared to the $8 \mathrm{AM}$ values.

significant decrease in plasma cortisol at 4 PM as compared to the 8 AM samples in both patients and controls $(F(1,9)=$ $10.6, p=.01$ and $F(1,9)=39.5, p<.0001$, respectively). The means of plasma cortisol levels at both time points were higher in patients $(F(1,18)=6, p=.03)$. No time $\times$ group interaction was observed.

\section{Basal Immunoglobulin Production in the Absence of $P W M$}

Basal immunoglobulin concentrations are given in Table 2; a graphic representation is given in Figures $1-4$. Within groups, the amounts of $\mathrm{IgG}$ and $\mathrm{IgM}$ produced at $8 \mathrm{AM}$ and at 4 PM were similar in patients and controls. Between-group comparison revealed no statistically significant differences, except for IgG production at 4 PM, which was significantly higher in controls in comparison with patients $(t=-2.3 ; d f=$ $17, p=.03)$.

\section{Basal PWM-Driven Immunoglobulin Production}

Within both the control and the patient group, no significant differences were observed between either $8 \mathrm{AM}$ and the $4 \mathrm{PM}$ IgG concentrations or between the $8 \mathrm{AM}$ and $4 \mathrm{PM} \operatorname{IgM}$ concentrations. Both $8 \mathrm{AM}$ and $4 \mathrm{PM}$ patient values were approximately twice as high as $8 \mathrm{AM}$ and $4 \mathrm{PM}$ control IgG values. These differences were statistically significant (8 AM: $t=3 ; d f=18 ; p=0.007$ and 4 PM: $t=2.2 ; d f=18 ; p=$ $0.04)$.

Although mean $8 \mathrm{AM}$ and 4 PM patient IgM values were respectively $130 \%$ and $155 \%$ of control IgM values, no significant differences were found between groups at both time points.

\section{HCO-Stimulated Immunoglobulin Synthesis in the Absence of $P W M$}

The $\operatorname{IgG}$ and $\operatorname{IgM}$ production in the absence of PWM is shown in Figures 1 and 2, respectively. MANOVA revealed a significant main $\mathrm{HCO}$ concentration effect on $\mathrm{IgG}$ and $\operatorname{IgM}$ production $(\mathrm{IgG}: F(4,14)=13.5, p=.0001 ; \operatorname{IgM}$ : $F(4.13)=5.6, p=.007)$. No interaction was present between concentration and time or between concentration and group, nor was a concentration $\times$ group $\times$ time effect present. $\mathrm{HCO}$ increased $\mathrm{IgG}$ production in $8 \mathrm{AM}$ and in $4 \mathrm{PM}$ samples in patients as well as in controls, preferentially at concentra- 
Table 2. Basal Immunoglobulin Production ${ }^{a}$

\begin{tabular}{|c|c|c|c|c|}
\hline \multirow[b]{2}{*}{ Group } & \multicolumn{2}{|c|}{$\operatorname{IgG}$} & \multicolumn{2}{|c|}{$\operatorname{Ig} M$} \\
\hline & $8 \mathrm{AM}$ & $4 \mathrm{PM}$ & $8 \mathrm{AM}$ & $4 \mathrm{PM}$ \\
\hline Patients & $1903.3 \pm 405.5$ & $1473.9 \pm 246.3 *$ & $1031.0 \pm 294.8$ & $740.6 \pm 140.9$ \\
\hline Controls ${ }^{h}$ & $2007.3 \pm 352.1$ & $2670.6 \pm 430.9$ & $965.7 \pm 167.3$ & $1678.7 \pm 506.0$ \\
\hline Patients & $5314.0 \pm 690.0^{* *}$ & $7308.8 \pm 1445.1 * * *$ & $1750.2 \pm 565.8$ & $2124.2 \pm 790.6$ \\
\hline Controls & $2478.0 \pm 560.3$ & $3615.2 \pm 722.8$ & $1317.1 \pm 482.3$ & $1370.1 \pm 460.9$ \\
\hline
\end{tabular}

"Concentrations are in $n g / 10^{h}$ cells and given as mean \pm SEM

${ }^{b} \mathrm{Ig}$ production in cultures without pokeweed mitogen (PWM)

'PWM-driven Ig production.

${ }^{*} p<.05$ as compared to controls.

${ }^{* *} p<.01$ and ${ }^{* * *} p<.05$ as compared to controls.

tions between $10^{-8}$ and $10^{-6}$ molar. A mean significant concentration effect was observed in patients $(F(4.6)=8.5, p=$ $.01)$ as well as in controls $(F(4,5)=7.8, p=.02)$. No time $\times$ concentration interaction was observed in either group. Subsequent analysis revealed significant increments at 8 AM and at 4 PM in both groups ( 8 AM patients: $F(4,6)=5.3, p$ $=.04$; controls: $F(4,5)=9.2, p=.02 ; 4$ PM patients: $F(4,6)=$ $6.5, p=.02$; controls: $F(4,5)=11, p=.01)$. In the absence of PWM, IgM production was not increased in patients, in contrast to a mean significant concentration effect in controls $(F(4,5)=5.3, p=.05$; time $\times$ concentration: NS). Subsequent analysis on the data of controls revealed an increase in the 4 PM samples only $(F(4,5)=6.2, p=.04)$.

\section{HCO-Stimulated Immunoglobulin Synthesis in the Presence of PWM}

The effect of $\mathrm{HCO}$ on IgG and IgM production in the presence of PWM is shown in Figures 3 and 4 . A significant

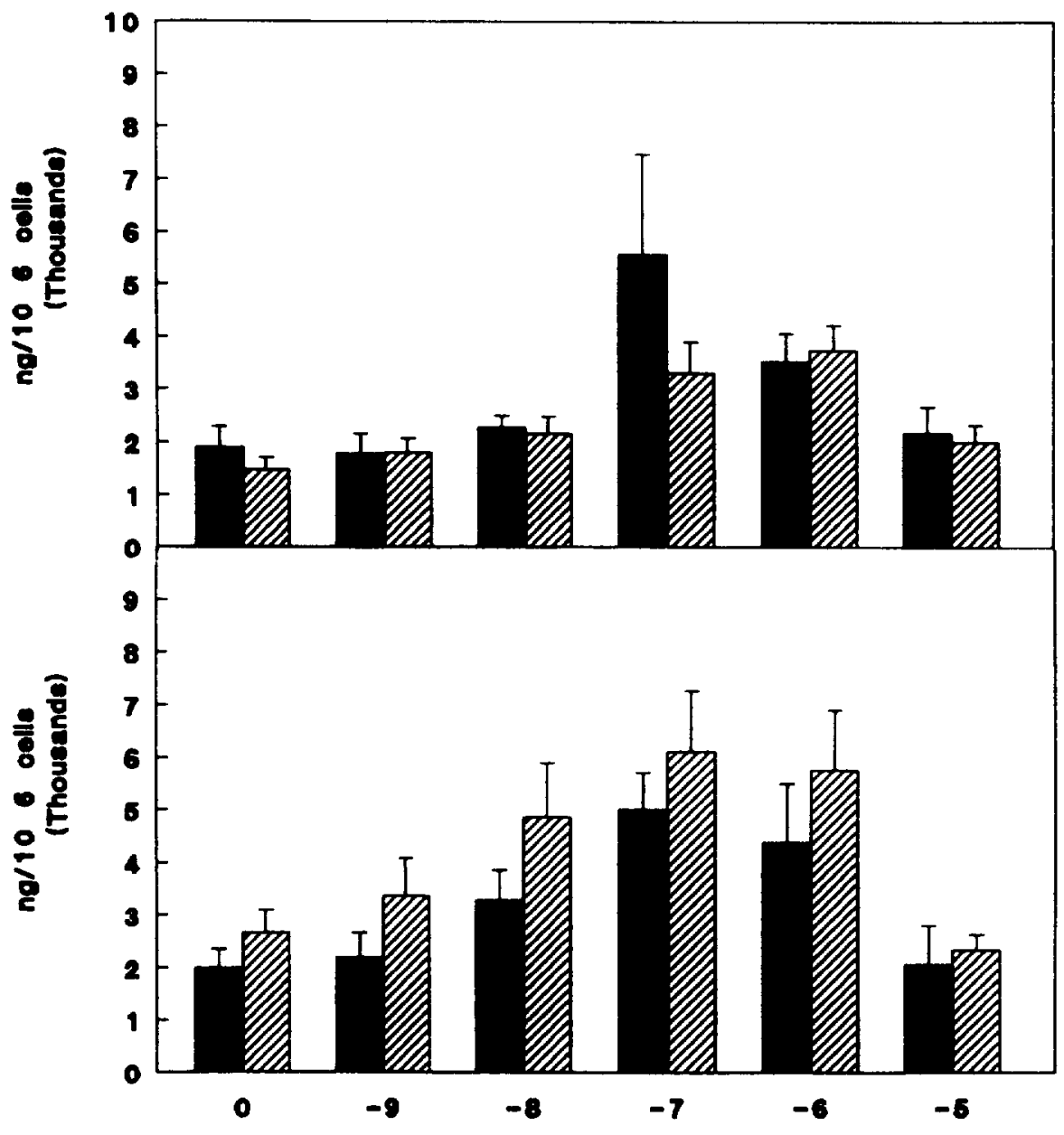

Figure 1. Effect of hydrocortisone (HCO) on in vitro IgG production Peripheral blood lymphocytes (PBLs) were cultured for 10 days in the absence of pokeweed mitogen (PWM). Equal volumes of medium alone or medium containing $\mathrm{HCO}$ in increasing concentrations $\left(10^{-9}-10^{-5} \mathrm{M}\right.$.) were added to the cultures. Data are expressed as mean \pm SEM. Upper panel indicates patient samples; lower panel indicates control samples. $\mathrm{HCO}$, in the concentration range of $10^{-9}-10^{-6} \mathrm{M}$, significantly increased IgG synthesis at both time points in both patient and control samples. Black bars: 8 AM samples; hatched bars: 4 PM samples. Abscissa: HCO concentration (molar; $x=10^{r}$ ). 


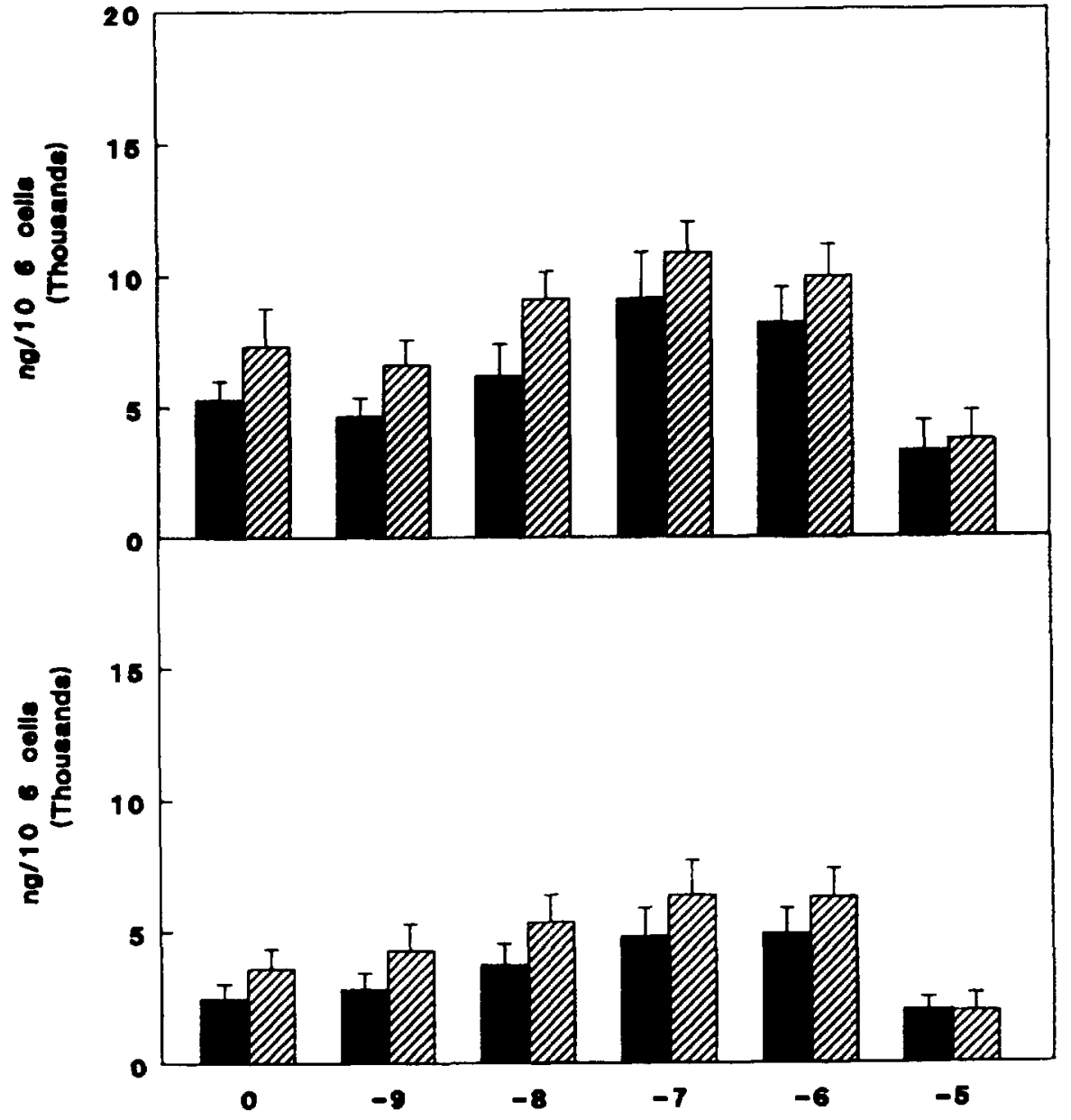

Figure 2. Effect of hydrocortisone $(\mathrm{HCO})$ on in vitro IgM production. Culture conditions were identical as described with reference to Figure 1. HCO, in the concentration range of $10^{-9}-10^{-6}$ $\mathrm{M}$, significantly increased IgM synthesis in controls in the 4 PM samples only (lower panel). IgM synthesis was not increased in patient samples at either time pint (upper panel). Black bars: 8 AM samples; hatched bars: 4 PM samples. Abscissa: HCO concentration (molar; $x$ $=10^{r}$ ). main concentration effect was found for the PWM-driven immunoglobulin production $(\operatorname{IgG}: F(4,14)=14, p<.0001$ : IgM: $F(4,14)=6.6, p=.003$ ). Similar to $\mathrm{HCO}$-stimulated immunoglobulin synthesis in the absence of PWM, in this culture condition no interactions were observed-be it either between concentration and time, between concentration and group, or between concentration, group and time.

A mean concentration effect was found on PWM-stimulated $\mathrm{IgG}$ production in patients $(F(4,5)=5.7, p=.04$, time $\times$ concentration: NS). Subsequent analysis revealed that this incremental production was mainly due to the effect of $\mathrm{HCO}$ in the $8 \mathrm{AM}$ samples ( $8 \mathrm{AM}: F(4.5)=6.6, p=.03 ; 4 \mathrm{PM}: \mathrm{NS}$ ). A mean concentration effect $(F(4.6)=11.9, p=.005$; concentration $\times$ time: NS) as well as incremental responses were observed in the PWM-stimulated IgG samples of the controls at both time points ( 8 AM: $F(4,6)=12.8, p=.004$; 4 PM: $F(4,6)=15, p=.003)$. PWM-stimulated IgM was not augmented by $\mathrm{HCO}$ in patients, whereas in the controls PWM-stimulated IgM production was raised by $\mathrm{HCO}$ (mean concentration effect: $F(4,6)=5.7, p=.03$; concentration $\times$ time: NS). In both $8 \mathrm{AM}$ and $4 \mathrm{PM}$ samples, an incremental response to $\mathrm{HCO}$ was observed $(8 \mathrm{AM}: F(4,6)=$ $10.9, p=.006 ; 4$ PM: $F(4,6)=7.5, p=.02)$.
As shown in Figures 1 and 3, most prominent effects of $\mathrm{HCO}$ are found on IgG production. The increments of the highest value observed relative to baseline values for IgG and IgM production of both patients and controls were found in cultures which lacked the presence of PWM. The percentages increase relative to baseline for IgG ranged from $229 \%-292 \%$; those for IgM ranged from $165 \%-203 \%$ for $8 \mathrm{AM}$ and $4 \mathrm{PM}$ values, respectively. PWM-driven cell cultures demonstrated less relative increments in $\mathrm{IgG}$ and IgM production. The percentages ranged from $147 \%-198 \%$ and from $123 \%-146 \%$, respectively.

At $10^{-5}$ molar $\mathrm{HCO}$, immunoglobulin production in all culture conditions was below basal values.

\section{Discussion}

In the present report we studied the effect of graded concentrations of $\mathrm{HCO}$ on Ig synthesis in vitro in lymphocytes from unipolar depressed patients and controls in relation to variations in plasma cortisol levels during the day. Comparison of $\operatorname{lgG}$ and $\mathrm{IgM}$ production in both culture conditions in both patient and control group yields consistent results. 


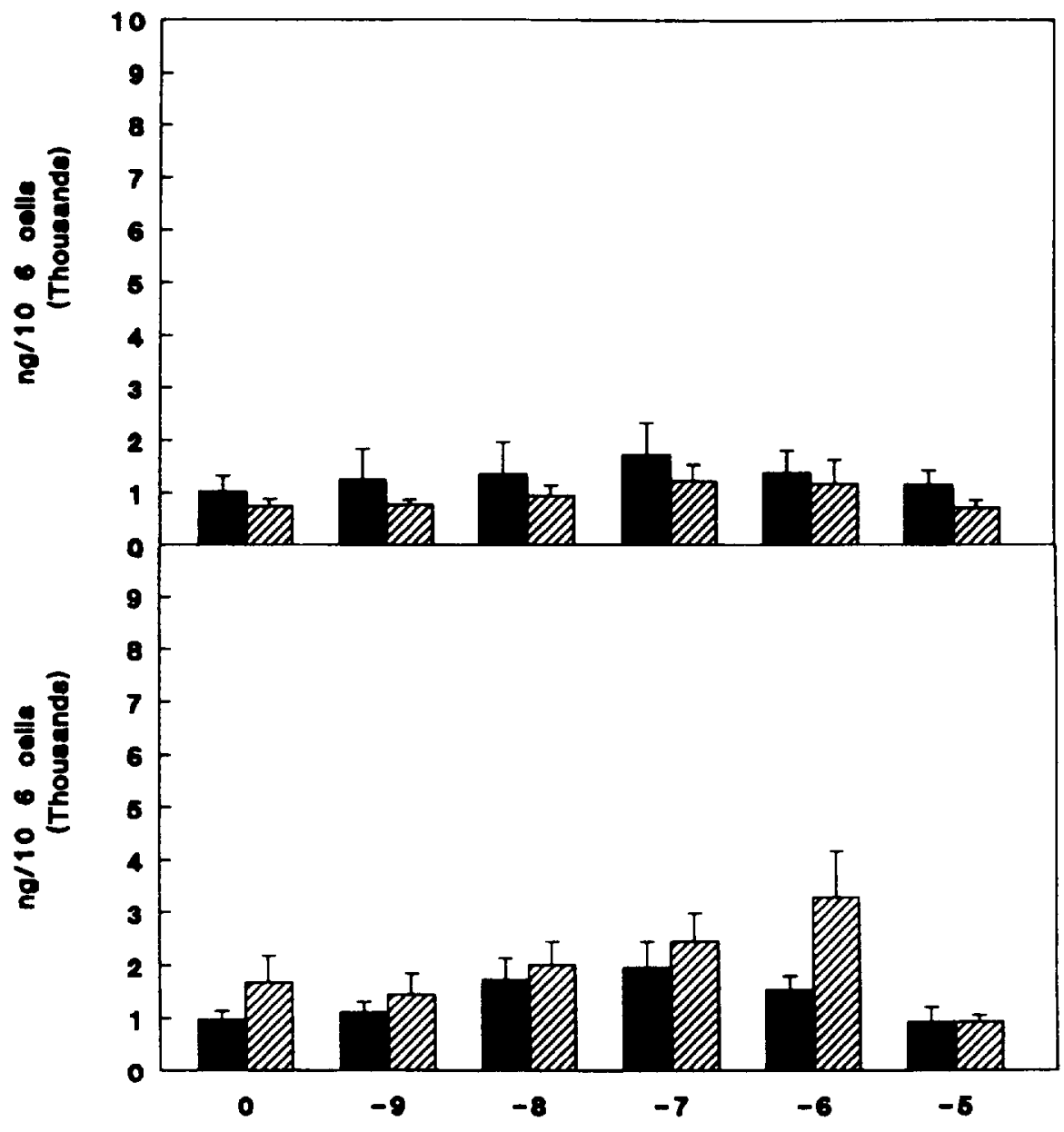

Figure 3. Effect of $\mathrm{HCO}$ on in vitro IgG production peripheral blood lymphocytes (PBLs) were cultured for 7 days in the presence of pokeweed mitogen (PWM). Equal volumes of medium alone or medium containing $\mathrm{HCO}$ in increasing concentrations $\left(10^{-9}-10^{-5} \mathrm{M}\right)$ were added to the cultures. $\mathrm{HCO}$, in the concentration range of $10^{-9}-10^{-6} \mathrm{M}$, significantly increased IgG synthesis at both time points in control samples (lower panel), whereas IgG synthesis in patient samples was increased in the 8 AM samples only (upper panel). Black bars: 8 AM samples; hatched bars: 4 PM samples. Abscissa: HCO concentration (molar; $x=10^{r}$ ).
Patient and control IgG production, cultured either in the presence or in the absence of PWM, showed significant incremental responses to $\mathrm{HCO}$, whereas $\mathrm{HCO}$ did not affect IgM production in the patient group. The absence of an effect of HCO on patient lymphocytes was observed in both culture conditions. This partly confirmed the expected existence of an in vitro difference in sensitivity to $\mathrm{HCO}$ between patient and control lymphocytes.

Prolonged hypercortisolemia may induce differential changes at the level of cytokines. Interleukin (IL)-2 and IL-6 play a role in isotype regulation and differentiation (Esser and Radbruch 1990). Furthermore, isotype switching is known to be regulated by soluble cytokines, such as IFN-gamma and IL-4 (Bertolini and Benson 1990). Thus, the observed difference in IgM production between controls and patients may have been associated with modulatory actions of prolonged hypercortisolemia within the patient group. Alternatively, hypercortisolemia may have led to regulatory changes within Ig producing plasma cells.

Whenever $\mathrm{HCO}$ was effective, a lower dose was required to stimulate IgG synthesis in controls as compared to patients. At $10^{-8}$ molar, an increase in $\operatorname{IgG}$ synthesis was observed in both culture conditions in controls, whereas incremental responses in patients were observed at $10^{-7}$ molar HCO. These results suggest that immunocompetent cells of depressed patients are apparently less sensitive to the modulating effects of $\mathrm{HCO}$. This observation adds to the assumption that Ig production is related to in vivo cortisol levels. The cells of the group exposed to the highest cortisol levels in vivo, i.e., the lymphocytes of the patient group, did show the least sensitivity to cortisol ex vivo. As patients were hospitalized, whereas the controls were taken from a community sample, hospitalization per se may have accounted for the difference observed. As was shown by Schleifer et al (1989) in a large study in major depressive disorder, the patient's hospitalization status was related to the mitogen response.

The finding of a lesser sensitivity to $\mathrm{HCO}$ in depressed patients is congruent with earlier studies on this subject. Natural killer cell activity in depressed patients has been shown to be less sensitive to the inhibiting effects of glucocorticoids in vitro (Miller et al 1987). In an attempt to relate the disturbances concerning the HPA axis observed in depressed patients to changes in immune function, hypore- 


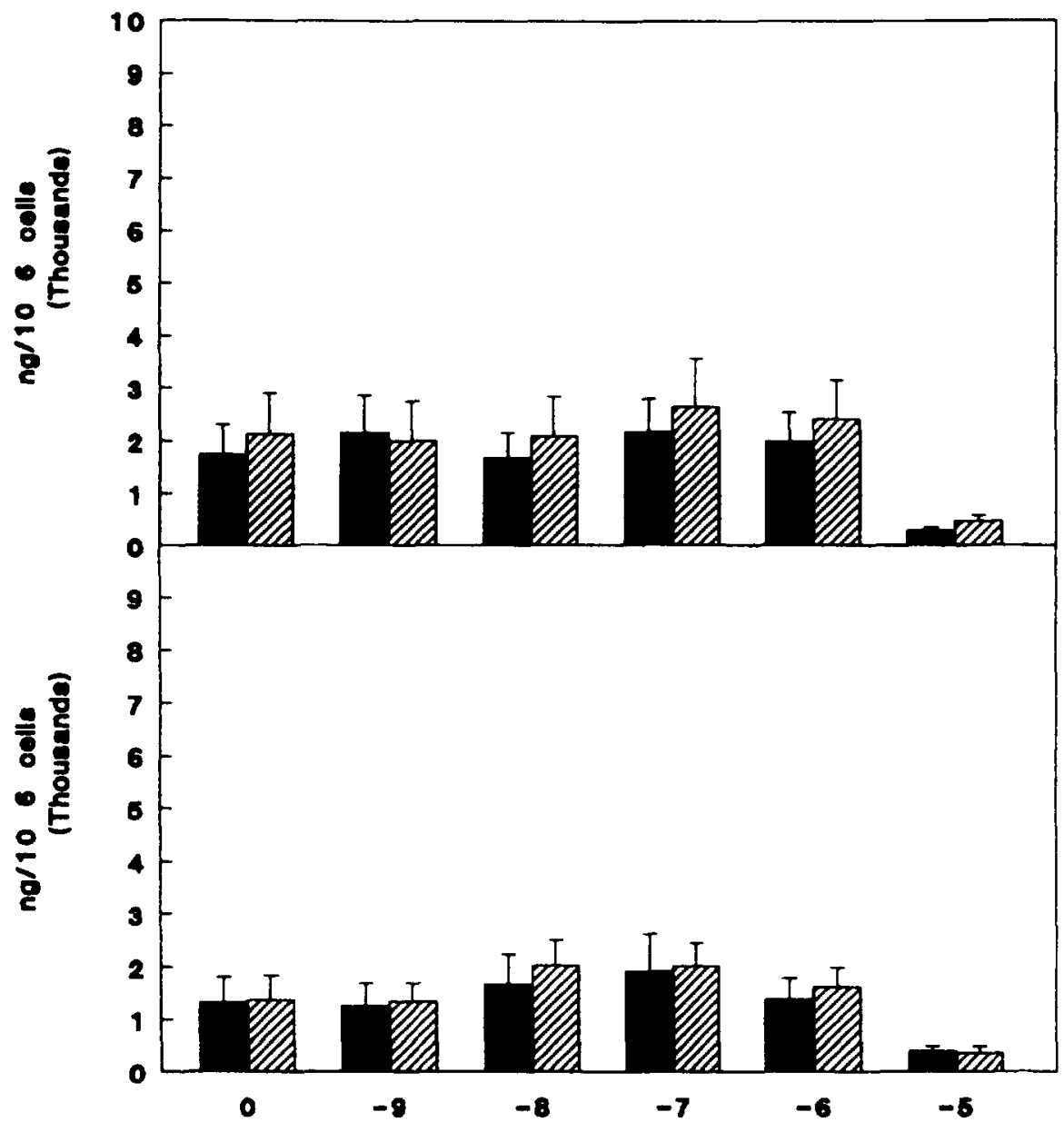

Figure 4. Effect of hydrocortisone $(\mathrm{HCO})$ on in vitro IgM production. Culture conditions were identical as described with reference to Figure 3. $\mathrm{HCO}$, in the concentration range of $10^{-9}-10^{-6}$ $M$, significantly increased IgM synthesis at both time points in control samples (lower panel), whereas IgM synthesis in patient samples was not augmented by HCO $n$ both the 8 AM and 4 PM samples (upper panel). Black bars: 8 AM samples; hatched bars: 4 PM samples. $A b$ scissa: HCO concentration (molar; $x=$ $10^{r}$ ). sponsiveness of mitogen-induced lymphocyte proliferation to glucocorticoids has been reported (Gormley et al 1985: Meltzer et al 1987). This hyporesponsiveness was related to post-dexamethasone plasma cortisol levels. Studying enumerative and functional measures of the immune system. Syvälathi et al (1985) reported no differences in the numbers of Ig secreting cells between depressed patients and controls. The authors used the plaque-forming cell assay and performed basal measures only, which may explain the discongruency between their results and ours. In a number of studies in depression, changes in T cells, B cells, or T cell subsets have been reported, though the results are conflicting (Schleifer et al 1989; Marazziti et al 1992). Quantative changes in the distribution of these parameters could be an inherent feature in depression, irrespective of plasma cortisol levels.

Unexpectedly, within-group comparison did not show a difference in Ig production between 8 AM and 4 PM samples. This result conflicts with the preceding argumentation of a putative association of the hypercortisolemia found in patients and a reduced sensitivity to $\mathrm{HCO}$.

Since in both groups the circadian variation of plasma cortisol levels appears to have been preserved, as is shown in Table 1, one would expect to find a different in vitro Ig response to $\mathrm{HCO}$ at different points in time within both groups if endogenous plasma cortisol levels were to play a role. Alternatively, the observed difference in immunoglobulin production between patients and controls could be the result of the combination of a "ceiling" and timing effect - the former being the consequence of increased cortisol levels in depressed patients at both 8 AM and 4 PM; the latter being the effect of a cumulative cortisol increase which outlasts the circadian changes in cortisol. When HCO and PWM are both added to the cultures, it appeared to be possible to enhance the response in depressed patients, which argues for a "ceiling" effect. In the absence of the additional stimulation provided by PWM, the potential influence of HCO may be limited by a combined "ceiling" and timing effect, i.e., that persistent increases in cumulative plasma cortisol in patients may have already influenced their circulating lymphocytes to such an extent that they could not recover between $8 \mathrm{AM}$ and $4 \mathrm{PM}$. An anologous situation is seen in the irreversible inhibiting effects of salicylates on platelet cyclooxygenase (Patrone et al 1985). 
In the $8 \mathrm{AM}$ as well as the 4 PM samples, basal PWM-driven IgG production was considerably higher in patients as compared to controls. An attractive explanation would be that cells exposed to higher in vivo glucocorticoid levels-as is the case in depressed patients-are more responsive to PWM, since one expects different in vivo levels of cortisol to alter the metabolic state of cells. Basal PWM-stimulated IgM levels did not differ between patients and controls, however, whereas no difference in basal IgG levels were observed in the $8 \mathrm{AM}$ and 4 PM cultures despite a significant fall in plasma cortisol in depressed patients. This argues against the aforementioned hypothesis but argues in favor of the influence of an increased cumulative plasma cortisol level over 24 hours. If this is what influences basal lymphocyte immunoglobulin production in the absence of PWM, and/or this effect is not able to be reversed for 24 hours, then once a certain cumulative plasma cortisol level is reached, one would not be able to detect differences in basal lymphocyte immunoglobulin production.

The relevance of the significantly higher basal level of IgG found in the 4 PM cell samples of controls cultured in the absence of PWM is questionable, since only slight differences were present. Rhythmic variations in total T cells, T helper, $\mathrm{T}$ suppressor, and $\mathrm{B}$ cells have been reported in healthy subjects (Thomson et al 1980; Abo et al 1981; Ritchie et al 1983; Miyawaki et al 1984 and Levi et al 1985, 1988), whereas the rhythmic variations of monocytes are less evident (Thomson et al 1980; Abo et al 1981). Indeed, some of these authors reported a relationship between endogenous cortisol levels and total lymphocytes or subsets (Thomson et al 1980; Abo et al 1981; Miyawaki et al 1984). Changes in the $\mathrm{T}$ helper/ $\mathrm{T}$ suppressor ratio as a result of a

\section{References}

Abo T, Kawate T, Itoh K, Kumagai K (1981): Studies on the bioperiodicity of the immune response. I. Circadian Rhythms of human T, B, and $\mathrm{K}$ cell traffic in the peripheral blood. $J$ Immunol 126:1360-1363.

Akahoshi T, Oppenheim JJ, Matsushima K (1988): Induction of high-affinity interleukin 1 receptor on human peripheral blood lymphocytes by glucocorticoid hormones. J Exp Med 167:924-936.

American Psychiatric Association (1987): Diagnostic and Statistical Manual of Mental Disorders, 3rd ed. rev. Washington DC: American Psychiatric Association.

Arya SK, Wong-Staal F, Gallo RC (1984): Dexamethasone mediated inhibition of human $T$ cell growth factor and gamma-interferon messenger RNA. J Immunol 133:273-276.

Ball R, Howlett T, Silverstone T. Rees L (1987): The interrelationship of beta endorphin, ACTH and cortisol in depressive illness: A controlled study. Psychol Med 17:31-37.

Bertolini JN, Benson EN (1990): The role of human interleukin-6 in B cell Isotype regulation and differentiation. Cell Immunol 125:197-209. circadian rhythm of subsets of lymphocytes could lead to substantial changes in secretion of IL- 2 or IL-6, both of which are essential in the PWM-driven Ig synthesis and differentiation of cells of the B cell lineage (Nakagawa et al 1987; Kishimoto and Hirano 1988).

We did not control for quantitative changes in lymphocyte subsets to occur. No inferences can thus be made as to whether these changes could have been related to any of the observed differences. The decline in the Ig production in most samples at a HCO concentration of $10^{-5}$ molar may be attributable to a cytotoxic effect of this high concentration.

In conclusion, the assumption of a relation between plasma cortisol levels and in vitro sensitivity of lymphocytes to $\mathrm{HCO}$ was not consistently demonstrated in this study. Simultaneous measurement of plasma IgG and IgM in both groups would have been of additional value in linking the in vivo and in vitro data. Additional evidence would thus have been gained in associating in vitro immune dysfunction in depression with in vivo functioning of the immune system. Longitudinal follow-up studies (e.g., Irwin et al 1992) are needed to extend our observations. Insight could thus be gained in the intricate relationship between altered in vitro immune reactivity, in vivo immune function, and increased vulnerability to immune-related diseases.

Furthermore, studies are needed to unravel the interrelationship between disturbances of the HPA axis, the often reported impaired immune function in depressive disorders and quantitative changes in circulating lymphocytes.

This study was supported by Medigon Grant 910-551-048

Bloem AC, van Hooff COM, Bast EJEG, Ballieux RE (1984): Mitogenic stimulation of malignant B cells. Chronic Lymphocytic leukemia Secretion of monoclonal $\operatorname{IgM}$ by in vitro-induced plasmablasts. Clin Exp Immunol 55:636-642.

Bowen DL, Fauci AS (1984): Selective suppressive effects of glucocorticoids on the early events in the human B cell activation process. J Immunol 133:1885-1890.

Bradley LM, Mishell RI (1981): Differential effects of glucocorticosteroids on the functions of helper and suppressor T lymphocytes. Proc Natl Acad Sci USA 178:3155-3159.

Brieva JA, de la Concha EG, Pascual-Salcedo D, Boottello A (1983): Modulatory effect of hydrocortisone on T-lymphocyte regulatory activity in PWM-driven Ig production. Clin Immunol Immunopathol 26:240-248.

Carroll BJ, Curtis GC, Mendels J (1976a): Neuroendocrine regulation in depression. I. Limbic system-adrenocortical dysfunction. Arch Gen Psychiatry 33:1039-1044.

Carroll BJ, Curtis GC, Mendels J (1976b): Neuroendocrine regulation in depression. II. Discrimination of depressed from nondepressed patients. Arch Gen Psychiatry 33:1051-1058. 
Cooper DA, Ducket M, Petts V. Penny R (1979): Corticosteroid enhancement of immunoglobulin synthesis by pokeweed mitogen-stimulated human lymphocytes. Clin Exp Immunol 37:145-151.

Coppen A, Metcalfe M (1987): The dexamethasone suppression test in depression. A world health organization collaborative study. Br J Psychiatry 150:459-462.

Cupps TR, Fauci AS (1982): Corticosteroid-mediated immunoregulation in man. Immunol Rev 65:133-155.

Cupps TR, Gerrard TL, Falkoff JM, Whalen G, Fauci AS ( 1985): Effects of in vitro corticosteroids on B cell activation, proliferation, and differentiation. $J$ Clin Invest 75:754-761.

Esser C, Radbruch A (1990): Immunoglobulin class switching: Molecular and cellular analysis. Annu Rev Immunol 8:717-735.

Fang VS, Tricou BJ, Robertson A, Meltzer HY (1981): Plasma ACTH and cortisol levels in depressed patients: Relation to the dexamethasone suppression test. Life Sci 29:931-938.

Fauci AS, Pratt KR, Whalen G (1977): Activation of human Blymphocytes IV. Regulatory effects of corticosteroids on the triggering signal in the plaque-forming cells response of human peripheral blood $\mathrm{B}$ lymphocytes to polyclonal activation. J Immunol 1 19:598-603.

Gillis S, Crabtree GR, Smith KA (1979): Glucocorticoid inhibition of $\mathrm{T}$ cell growth factor production. I. The effect on mitogeninduced lymphocyte proliferation. J Immunol 123:1624-1631.

Gormley G, Lowy MT, Reder AT, Hospelhorn VD, Antel JP. Meltzer HY (1985): Glucocorticoid receptors in depression: Relationship to the dexamethasone suppression test. Am J Psychiatry 142:1278-1284.

Grabstein K, Dower S, Gillis S, Urdal D, Larsen A (1986): Expression of interleukin 2, interferon-gamma and the IL-2 receptor by human peripheral blood lymphocytes. J Immunol 136:4503-4508.

Grayson J. Dooley NJ, Koski IR, Blaese M( 1981): Immunoglobulin induced production induced in vitro by glucocorticoid hormones. $T$ cell-dependent stimulation of immunoglobulin production without $\mathrm{B}$ cell proliferation in cultures of human peripheral blood lymphocytes. J Clin Invest 68:1539-1547.

Hamilton M (1960): A rating scale for depression. J Neurol Neure surg Psychiatry 23:56-62.

Irwin M, Lacher U, Caldwell C (1992): Depression and reduced natural killer cytotoxicity: A longitudinal study of depressed patients and control subjects. Psychol Med 22:1045-150.

Kathol RG, Jaeckle RS, Lopez JF, Meller WH (1989): Pathophysiology of HPA axis abnormalities in patients with major depression: An update. Am J Psychiatry 146:31 1-317.

Kishimoto T, Hirano T (1988): Molecular regulation of B-lymphocyte response. Annu Rev Immunol 6:485-512.

Kronfol Z, House JD, Silva J Jr, Greden J, Carroll BJ ( 1986): Depression, Urinary free cortisol excretion and lymphocyte function. BrJ Psychiatry 148:70-73.

Levi FA, Canon C, Blum JP, Mechkouri M, Reinberg A, Mathé G (1985): Circadian and/or circahemidian rhythms in nine lymphocyte-related variables from peripheral blood of healthy subjects. J Immunol 134:217-222.

Levi FA, Canon C, Touitou Y, et al (1988): Circadian rhythms in circulating $\mathrm{T}$ lymphocyte subtypes and plasma testosterone. total and free cortisol in five healthy men. Clin Exp Immunol 71:329-335.
Marazziti D, Ambrogi F, Vanacore R (1992): Immune cell imbalance in major depressive and panic disorders. Neuropsychobio$\log y$ 26:23-26.

McMillan VM, Dennis GJ, Glimcher LH, Finkelman FD, Mond JJ (1988): Corticosteroid induction of $\mathrm{Ig}^{+} \mathrm{Ia}^{-} \mathrm{B}$ cells in vitro is mediated via interaction with the glucocorticoid cytoplasmic receptor. J Immunol 140:2549-2555.

Meltzer HY, Lowy MT, Koenig JI (1987): The hypothalamic pituitary adrenal axis in depression. In Nerozzi D, Goodwin FK, Costa E (eds), Hypothalamic Dysfunction in Neuropsychiatric Disorders. New York: Raven Press, pp 165-182.

Miller AH, Asnis GM, Lackner C, Norin AJ (1987): The in vitro effect of cortisol on natural killer cell activity in patients with major depressive disorder. Psychopharmacol Bull 23:502504 .

Miyawaki T, Taga K, Nagaoki K, Seki H, Suzuki Y, Tanigucki N (1984): Circadian changes of T lymphocyte subsets in human peripheral blood. Clin Exp Immunol 55:618-622.

Nakagawa N, Nakagawa T, Volkman DJ, Ambrus JL Jr, Fauci AS (1987): The role of Interleukin 2 in inducing Ig production in a pokeweed mitogen-stimulated mononuclear cell system. $J \mathrm{Im}$ munol 138:795-801.

Nerozzi D, Santoni A, Bersani G, et al (1989): Reduced natural killer cell activity in major depression: Neuroendocrine implications. Psychoneuroendocrinology 14:295-301.

Orson FM, Grayson J, Pike S, De Seau V, Blaese RM (1983): T cell-replacing factor for glucocorticosteroid-induced immunoglobulin production. A unique steroid dependent cytokine. $J$ Exp Med 158:1473-1482.

Patrone C, Ciabattoni G, Patrignani P, et al (1985): Clinical pharmacology of platelet cyclooxygenase inhibition. Circulation $72: 1177-1184$

Pfohl B. Sherman B, Schlechte J, Winokur G (1985): Differences in plasma $\mathrm{ACTH}$ and cortisol between depressed patients and normal controls. Biol Psychiatry 20:1055-1072.

Reed JC, Abidi AH, Alpers JD, Hoover RG, Robb RJ, Nowell PC (1986): Effect of cyclosporin A and dexamethasone on interleukin-2 receptor gene expression. J Immunol 137:150154.

Ritchie AWS, Oswald I, Spedding Micklem H, et al (1983): Circadian variation of lymphocyte subpopulations: A study with monoclonal antibodies. Br Med J 286:1773-1775.

Roy A, Pickar D, Paul S, Doran A, Chrousos GP, Gold PW (1987): CSF corticotropin-releasing hormone in depressed patients and normal subjects. Am J Psychiatry 144:641-645.

Schleifer SJ, Keller SE, Meyerson AT, Raskin MJ, Davis KL, Stein M (1984): Lymphocyte function in major depressive disorder. Arch Gen Psychiatry 41:484-486.

Schleifer SJ, Keller SE, Bond RN, Cohen J, Stein M (1989): Major Depressive Disorder and immunity: Role of age, sex, severity and hospitalization. Arch Gen Psychiatry 46:81-87.

Sierakowski S, Goodwin JS (1988): Mechanism of action of glucocorticoid-induced immunoglobulin production: II. Requirement for fetal calf serum. Clin Exp Immunol 71:198-201.

Smith RS, Sherman RA, Middleton E Jr (1972): Effect of hydrocortisone on immunoglobulin synthesis and secretion by human peripheral lymphocytes in vitro. Int Arch Allergy Appl Immunol 43:859-870. 
Snyder DS, Unanue ER (1982): Corticosteroids inhibit murine macrophage Ia expression and interleukin 1 production. $J \mathrm{Im}$ munol 129:1803-1805.

Staruch MJ, Wood DD (1985): Reduction of serum Interleukin-1like activity after treatment with dexamethasone. J Leukocvte Biol 37: 193-207.

Syvälahti E, Eskola J, Ruuskanen O, Laine T (1985): Nonsuppression of cortisol in depression and immune function. Prog Neuropsychopharmacol Biol Psychiatry 9:413-422.
Thomson SP, McMahon LJ, Nugent CA (1980): Endogenous cortisol: A regulator of the number of lymphocytes in peripheral blood. Clin Immunol Immunopathol 17:506-514.

Thijssen JHH, van den Berg JHM, Adlercreutz H, et al (1980): The determination of cortisol in human plasma: Comparison of seven assays. Clin Chim Acta 100:39-46.

Woloski BMRN, Smith EM, Meyer WJ III, Fuller GM, Blalock JE (1985): Corticotropin-releasing activity of monokines. Science 230:1035-1037. 